University of Nebraska - Lincoln

DigitalCommons@University of Nebraska - Lincoln

\title{
On-Farm Evaluation of a Humic Product in lowa (US) Maize Production
}

\author{
Dan C. Olk \\ USDA-ARS, dan.olk@ars.usda.gov \\ Dana L. Dinnes \\ USDA-ARS \\ Chad Callaway \\ Innovative Crop Solutions \\ Mike Raske \\ Innovative Crop Solutions
}

Follow this and additional works at: https://digitalcommons.unl.edu/usdaarsfacpub

Olk, Dan C.; Dinnes, Dana L.; Callaway, Chad; and Raske, Mike, "On-Farm Evaluation of a Humic Product in lowa (US) Maize Production" (2013). Publications from USDA-ARS / UNL Faculty. 1292.

https://digitalcommons.unl.edu/usdaarsfacpub/1292

This Article is brought to you for free and open access by the U.S. Department of Agriculture: Agricultural Research Service, Lincoln, Nebraska at DigitalCommons@University of Nebraska - Lincoln. It has been accepted for inclusion in Publications from USDA-ARS / UNL Faculty by an authorized administrator of DigitalCommons@University of Nebraska - Lincoln. 


\title{
On-Farm Evaluation of a Humic Product in Iowa (US) Maize Production
}

\author{
Dan C. Olk, Dana L. Dinnes, Chad Callaway, and Mike Raske
}

\begin{abstract}
The benefit to corn (Zea mays L.) production of a humic product derived from lignite was evaluated for 3 years under otherwise conventional crop management in Iowa farmers' fields. A liquid extract, it was applied at a rate of $3.57 \mathrm{~L} \mathrm{ha}^{-1}$, generally as a foliar spray mixed into routine pesticide applications during early stages of crop growth. In each of 3 years, hand-sampled corn plants collected at physiological maturity in 30-35 farmers' fields across Iowa showed a significant increase in grain weight with product application in 70-80\% of the cases, covering a range of soil types and grain yield levels. Mean increases were $630-940 \mathrm{~kg} \mathrm{ha}^{-1}$, and these were inflated, as expected, compared to a limited number of yield increases estimated by mechanical combine, typically $310-630 \mathrm{~kg} \mathrm{ha}^{-1}$, or about $5 \%$ of normal yield levels. Grain weight increases were associated with longer, thicker, and heavier cobs and slightly larger stover biomass. Plant nutrient concentrations were not affected at harvest. In-season measurements in a few intensively monitored farmers' fields associated product application with slightly taller plants, increased leaf area, earlier onset of pollination, extended grain filling, and delayed senescence, i.e., extended duration of photosynthesis and decayed rotting of stems. Limited visual observations indicated great proliferation of roots, especially lateral roots. Ongoing data assessment will identify any environmental factors of product efficacy, an issue that to date remains unexplored in the humic product literature. Initial studies of alfalfa (Medicago sativa L.) found biomass increases with product application of 7-29\%. A newly begun corn trial on nitrogen fertilizer response will estimate the amount of $\mathrm{N}$ fertilizer input that can be replaced by humic product application to save input costs and mitigate environmental degradation. The humic product increased economic yield in a large
\end{abstract}

\author{
D.C. Olk $(\bowtie) \cdot$ D.L. Dinnes \\ USDA-ARS, National Laboratory for Agriculture and the Environment, Ames, IA 50011, USA \\ e-mail: dan.olk@ars.usda.gov \\ C. Callaway • M. Raske \\ Innovative Crop Solutions, Radcliffe, IA 50230, USA
}


majority of cases by amounts that were agronomically modest but economically significant. Future work will expand to soybean (Glycine $\max$ (L.) Merr.) production.

Keywords Humic product • Maize • Grain yield

\section{Introduction}

Speculation has existed for decades regarding the capacity of humic products to enhance crop growth in field conditions. Yet only in recent years have many researchers begun rigorous evaluations of this potential effect. Little such work has been done for maize in the corn belt of the central United States. Central Iowa has among the highest grain yields in the corn belt, as its soils are rich in soil organic matter and nutrients, and water is available for much of the growing season. Hence, this region represents a challenging setting for demonstrating enhanced crop growth through addition of humic products. We undertook such an evaluation for 3 years, examining the effect of one humic product from a landscape-scale perspective.

\section{Materials and Methods}

The humic product was a liquid extract of lignite and is sold as "Yield Igniter" by Innovative Crop Solutions. ${ }^{1}$ It was sprayed onto the soil or growing plants at any of several crop growth stages in multiple farmers' fields in Iowa during the 2009-2011 seasons. Replicated treatments of different application times were installed in a few fields, and plant growth was monitored during the growing season, including leaf area, internodal distance, and plant height. At physiological maturity, a 1-m section of plants was removed from each treatment in these fields. The plants were partitioned into grain, cob, and stover, and each part was dried, weighed, and analyzed for nutrients. This sampling at physiological maturity was repeated in 30-35 farmers' fields where the product had been sprayed onto the maize crop at a crop growth stage chosen by each farmer.

\footnotetext{
${ }^{1}$ Mention of companies, trade names, or commercial products in this abstract is solely for the purpose of providing specific information and does not imply recommendation or endorsement by the USDA.
} 


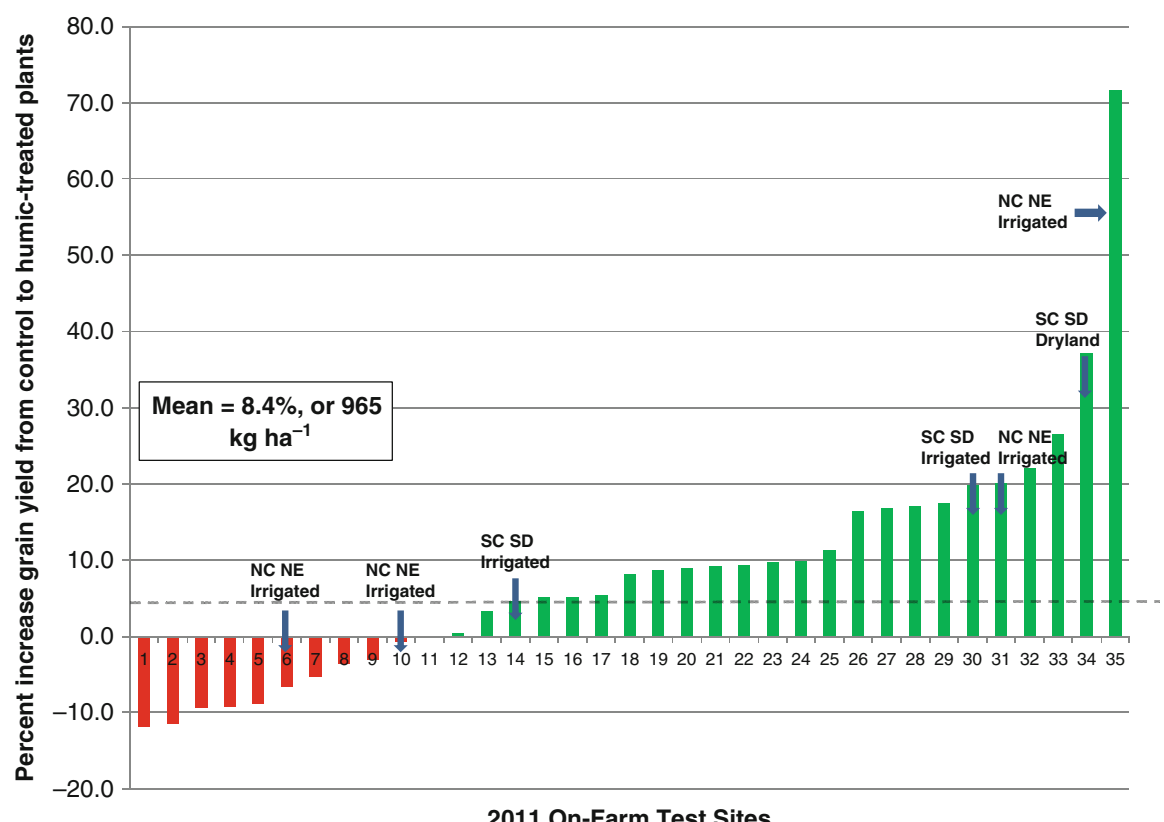

Fig. 1 Change in maize grain yield with humic product application in 35 Iowa (US) farmers' fields, based on one-meter sections of harvested maize plants, 2011. NE Nebraska, SD South Dakota, $N C$ north central, $S C$ south central

\section{Results and Discussion}

In each of the 3 years, addition of the humic product caused increased grain mass in $70-80 \%$ of the farmers' fields (Fig. 1), and this effect was significant $(P<0.01)$ in each year. Mass of the cob and the stover (the remainder of the plant) also increased. Mean mass of each grain did not increase noticeably, nor did the number of kernel rows. Cob length increased significantly with product application. All fields in 2009 and 2010 were in Iowa. In 2011, six additional fields were tested in drier locales in states to the west, Nebraska and South Dakota. These fields provided some of the strongest responses to the product.

In Iowa fields, leaf area increased significantly with product application in four of five fields tested. This benefit appeared to be of finite duration, as product application at an early growth stage had a greater effect on the early and middle leaves than on the final leaves. Plant height was significantly $(P<0.05)$ increased, due to a significantly longer first internode right above the soil surface and numerically longer lengths for most other internodes. Limited visual observations indicated great proliferation of roots, especially lateral roots.

Product application resulted generally in delayed senescence of the plant. In perhaps $90+\%$ of the cases, plants receiving the product had stronger stalks at physiological maturity (sap still flowed through their fully intact interiors), while in 
contrast the stalks of unamended plants were dry, frail, and beginning to rot. In 2011, which had a droughty second half of the growing season, at physiological maturity leaves still retained some greenness with product application in a number of fields, while leaves of adjacent unamended plants were yellow. In the single year (2009) when grain-filling duration was monitored, its beginning at pollination was accelerated by 3 days with product application in all four fields monitored, and its end at physiological maturity was delayed by 3-6 days in both fields monitored, extending grain-filling duration by $10 \%$. Some benefit to crop growth was observed for all application times, ranging from preemergence of the crop to sixth vegetative leaf, but the earlier application times provided numerically slightly stronger effects.

Soil properties and crop management practices affected somewhat the impact of the humic product on grain yield. Its benefit appeared minimized in wet soils, and it was subdued at high yield levels or in fertile, carbon-rich soils. Ongoing data assessment will further identify any environmental factors of product efficacy, an issue that to date remains unexplored in the humic product literature.

We are now testing this product in a few crops other than maize. Initial studies of alfalfa (Medicago sativa L.) found biomass increases with product application of 7-29\%, and further measurements will be collected in 2012 and 2013. A newly begun maize trial on nitrogen fertilizer response will estimate the amount of $\mathrm{N}$ fertilizer input that can be replaced by humic product application to save input costs and mitigate environmental degradation while maintaining yield targets. Studies in 2012 began in soybean (Glycine max (L.) Merr.) fields.

This humic product increased maize economic yield in a large majority of cases by amounts that were agronomically modest but economically significant.

The sole cost incurred in using this product was its purchase, about US $\$ 25 \mathrm{ha}^{-1}$, while the average increase in market value of maize grain yield with product application was at least three times greater. With farm sizes in Iowa often exceeding $400 \mathrm{ha}$, the farm-scale economic return becomes meaningful. This product does not guarantee increased economic returns, but in our study it enhanced the probability of increased returns for maize. 